\title{
Array comparative genomic hybridization in prenatal diagnosis of first trimester pregnancies at high risk for chromosomal anomalies
}

\author{
Isabel Filges ${ }^{1,3^{*}}$, Anjeung Kang ${ }^{2}$, Vanessa Klug ${ }^{1}$, Friedel Wenzel ${ }^{1}$, Karl Heinimann ${ }^{1}$, Sevgi Tercanli ${ }^{2}$ and Peter Miny ${ }^{1}$
}

\begin{abstract}
Objective: To describe the diagnostic performance of array comparative genomic hybridization $(\mathrm{aCGH})$ as a potential first line diagnostic method in first trimester high risk pregnancies.

Method: In a retrospective study we performed aCGH using a targeted array BAC platform (Constitutional Chip ${ }^{\circledR}$ 4.0, PerkinElmer, Turku Finland, median resolution $600 \mathrm{kB}$ ) and the Affymetrix Cytogenetics ${ }^{\circledR}$ Whole Genome $2.7 \mathrm{M}$ array (at a resolution of $400 \mathrm{kB}$ ) on 100 anonymized prenatal samples from first trimester high risk pregnancies with normal conventional karyotype. We studied the technical feasibility and turn-around-time as well as the detection rate of pathogenic submicroscopic chromosome anomalies and CNVs of unknown significance.

Results: We obtained results in 98 of 100 samples in 3 to a maximum of 5 days after DNA extraction. At the given resolution we did not identify any additional pathogenic CNVs but two CNVs of unknown significance in the chromosomal regions 1q21.1q21.2 (deletion) and 5p15.33 (duplication) (2\%).

Conclusion: In accordance with a growing number of reports this study supports the concept that aCGH at a resolution of 400-600kB may be used as a first line prenatal diagnostic test with high diagnostic safety and rapid turn-around time in high-risk first trimester pregnancies. Detection rate of CNVs of unknown significance, considered as a major hindrance for replacing conventional karyotyping by aCGH, is $2 \%$, but the diagnosis of additional submicroscopic anomalies in this heterogeneous group of patients seems to be rare.
\end{abstract}

Keywords: Prenatal diagnosis, Array comparative genomic hybridization, ArrayCGH, aCGH, First trimester High risk, CVS

\section{Background}

The current approach to prenatal diagnosis of chromosomal anomalies is a non-invasive risk assessment for trisomy 21 and other aneuploidies by first trimester or integrated risk screening offered to all pregnant women. If these screening approaches reveal an increased risk standard chromosome analysis after chorion villous sampling (CVS) or amniocentesis (AC) is offered for the detection of numerical or structural chromosome aberrations.

\footnotetext{
* Correspondence: Isabel.Filges@unibas.ch

${ }^{1}$ Dr. med. Isabel Filges, Division of Medical Genetics, University Children's

Hospital and Department of Biomedicine, University of Basel,

Burgfelderstrasse 101, Building J, CH-4055, Basel, Switzerland

3Department of Medical Genetics, BC Children's and Women's Hospital, Child and Family Research Institute, University of British Columbia, Box 153, 4480

Oak Street, Vancouver, BC V6H 3V4, Canada

Full list of author information is available at the end of the article
}

The current approach of risk screening has significantly reduced the number of invasive procedures and has increased the detection rate at the same time $[1,2]$. Recently, detection of aneuploidy by using massively parallel sequencing approaches as well as fetal-specific DNA-methylation ratio on free fetal DNA in maternal circulation (so-called non-invasive prenatal diagnosis) has been successful and appears to have the potential to replace first trimester screening in the near future [3-8].

In clinical practice, however, pregnancies at high risk for aneuploidy for various reasons do not infrequently show a normal conventional chromosome analysis. The limited clinical information provided by the ultrasound image of the fetal anatomy and physical development does usually not allow the diagnosis of a specific disease to be confirmed by appropriate testing which leaves

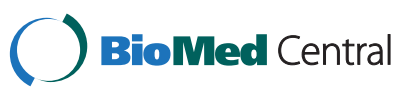


parents in a dilemma of accepting a high risk for a condition with developmental delay and/or mental retardation of unknown severity or opting for a termination of the pregnancy.

Array comparative genomic hybridization (aCGH), which can provide a much higher resolution than conventional karyotyping, has now become the genetic test of first choice for postnatal investigation of intellectual disability (ID) and/or multiple congenital anomalies (MCA) detecting causal submicroscopic chromosomal imbalances i.e. microdeletion- and microduplication syndromes in $10-20 \%$ in these groups of patients $[9,10]$. A limited number of prenatal studies using array based methods have been conducted on fetuses with normal karyotypes focusing on high risk for aneuploidy defined by ultrasound anomalies [11-14] showing variable detection rates superior to conventional cytogenetics. Still, important questions are unanswered as to the appropriate platform and resolution, clinical indications, detection rate for pathogenic imbalances and copy number variations with unknown significance as well as costbenefit and standardisation aspects in particular to the necessary follow-up studies by conventional karyotyping and/or fluorescence-in-situ hybridization (FISH) [15,16]. In particular, CNVs of unknown clinical significance are considered to be the major hindrance of introducing array-based technologies into prenatal diagnosis as a first-line approach. Therefore at present, array diagnosis has only been proposed as an adjunct tool in the investigation of pregnancies with congenital anomalies and normal karyotype [17].

The significant advances in earlier screening and diagnostic testing for genetic disorders have shifted prenatal diagnosis from screening and diagnosis form the second trimester to the first trimester. In experienced tertiary ultrasound centers, the detection rate of fetal structural anomalies is as high as $40 \%$ in the first trimester ultrasound [18]. As first trimester screening aims to provide early diagnosis we consider chorionic villi sampling as the invasive method of choice. Array-based methods have the potential to significantly reduce the turnaround time and replace rapid testing by interphase FISH, QF-PCR or MLPA. aCGH on chorionic villi could offer a time-saving and early approach to a comprehensive and high resolution assessment of chromosomal abnormalities following first trimester risk screening.

Between May 2009 and January 2011 we conducted a retrospective study in our tertiary antenatal referral center with a high proportion of high risk pregnancies applying array analysis for pregnancies at high risk for chromosomal anomalies in the first trimester. As a standard of care in our center CVS is offered to women with a confirmed high risk first trimester pregnancy allowing a comprehensive low resolution karyotype in a
$24 \mathrm{~h}$ direct preparation followed by a conventional karyotype from cultured cells. Amniocentesis for the same indication is performed when CVS cannot be considered for obstetrical reasons or because of patients' personal preferences. We used aCGH on anonymized cryopreserved stored or remaining tissue from prenatal invasive testing from pregnancies at a high risk for chromosomal anomalies and normal karyotype. Details on analyzed tissues are given in Table 1. High risk was defined as a high risk in first trimester screening (1:10 or higher) or nuchal translucency $>3 \mathrm{~mm}$ or both, intrauterine growth retardation and/or fetal malformation(s). Data on the clinical indication for prenatal invasive diagnosis, karyotype result, tissue and DNA quality as well as results of aCGH analysis including pathogenic CNVs not detected by conventional chromosome analysis as well as CNVs of unknown significance were collected.

The goal of our study was to optimize technical aspects and to evaluate technical feasibility, safety and the potential of automation of aCGH in first trimester prenatal diagnosis as a first line test with the ultimate goal to replace direct preparation of chorionic villi that is used for rapid testing in our laboratory as well as other rapid aneuploidy testing methods. In addition detection rates of additional pathogenic variants compared to the rate of undesirable variants of unknown significance were assessed.

\section{Results}

After technical optimization of DNA sample quality two analyzed samples (2\%) failed to give interpretable results. In general, DNA quality of cryopreserved cell cultures, depending also on the period of storage, was lower than DNA quality of fresh tissue. Preferably, DNA extracted from direct chorionic tissue was used for analysis. However, DNA from cultured cells was used when direct villi were either not available any more or its total amount was insufficient for additional array analysis. In our retrospective cohort defined by first trimester high risk for chromosomal anomalies and normal conventional chromosome analysis we did not identify any single additional clear-cut chromosomal anomaly by using aCGH. Detection rate of

Table 1 Distribution of sample types used in this study

\begin{tabular}{lll}
\hline & Tissue & Number of samples \\
\hline CVS & Stored & 13 \\
& cryopreserved & \\
& Direct villi & 23 \\
& Cultures villi & 50 \\
Amniocentesis & Cultured amniocytes & 13 \\
others & Pleural liquid & 1 \\
Total & & $\mathbf{1 0 0}$
\end{tabular}


CNVs of unknown significance was $2 \%$. One deletion was found in the chromosomal region 1q21.1q21.2 (CVS sample) not overlapping with the recurrent 1q21.1 deletion syndrome and another CNV (CVS sample) was identified in the cri-du-chat critical region, but represented a duplication to which thus far no phenotype is attributed (Table 2). aCGH provided additional information on the extent of the aberrations for two CVS samples for which conventional karyotyping had revealed structural chromosomal anomalies. In one fetus with malformations additional material on the long arm of chromosome 20q turned out to be a complete trisomy of $20 \mathrm{q}$ with final karyotype designation 46,XY,der(20)(20pter$>$ 20qter::20q11.21- > 20q13.33).arr 20q11.21q13.33(20,06 $6,572-49,655,888) \times 3$. A pregnancy with high risk in first trimester screening but normal ultrasound was diagnosed with a terminal deletion $9 \mathrm{p}$ encompassing the region 9p24.3p24.2 (199,111-4,401,383; hg18) and a duplication of 2p25.3p24.3 (19,477-14,322,431; hg18) allowing more precise genotype-phenotype correlation particularly for the terminal $9 \mathrm{p}$ deletion. The extent explained a normal ultrasound but implies a high risk for a global developmental delay [19] and thus allows a more reliable outcome prediction.

We encountered 3 remarkable situations with mosaicism of the fetoplacental unit. The specific issue of placental mosaicism and its consequences for the diagnostic accuracy have been addressed separately [20]

\section{Discussion}

In our retrospective study we failed to show that the detection rate of aCGH at a median resolution of $600 \mathrm{~kb}$ (400 kb respectively) is superior to conventional chromosome analysis. The detection rate of CNVs of unknown significance, discussed as a major hindrance to the introduction of aCGH in prenatal diagnosis, is at $2 \%$. Due to the retrospective anonymous design of the study we were not able to confirm or exclude familial segregation to further elucidate pathogenicity.

In contrast to the existing reports focusing on detection rates in pregnancies with fetal malformations mostly diagnosed by second trimester sonography we dealt with pregnancies showing a high risk for chromosomal anomalies in the first trimester for heterogeneous clinical reasons. Clinical indications for invasive prenatal testing were increased nuchal translucency $(>3 \mathrm{~mm})$ and/or elevated first trimester test risk in 57, more than a half, of the referred samples. Recently, Leung et al. reported on the detection of 4 additional pathogenic submicroscopic anomalies ranging from 1.2 to $7.9 \mathrm{Mb}$ when using a custom designed array at a median resolution of $100 \mathrm{~kb}$ in a series of 48 pregnancies with nuchal translucency more than $3.5 \mathrm{~mm}$ [21]. However, 2 of these fetuses had additional sonographic anomalies. Both sample sizes, Leung's and our's, are comparably small and the overall detection rate of pathogenic CNVs in fetuses with increased NT seems to be rather low, but might nevertheless require further and larger studies. The progression or regression of cystic hygroma should probably be taken into account for phenotype correlations, and other monogenic disorders such as Noonan or CFC -syndrome caused by mutations in genes of the RAS-signalling pathway, seem to be a reasonable differential diagnosis to consider [22-24] (and personal communication Yntema H.G. European Society Human Genetics C07.6).

In our approach we have chosen a comparably low and targeted resolution of a median $600 \mathrm{~kb}$ resolution for the BAC-array in order to avoid CNVs of unknown clinical significance. In a prenatal setting unknown CNVs can represent a particular challenge as phenotypic data are sparse compared to the possibilities of obtaining phenotypic details on postnatal patients. In addition, the potential option of pregnancy termination requires a higher level of interpretation accuracy. Our resolution might be too cautious especially considering our low detection rate of pathogenic imbalances. Most postnatally identified pathogenic microdeletion- and duplication syndromes, however, are caused by pathogenic CNVs larger than $400 \mathrm{~kb}$ [25]. Therefore, a whole genome resolution of $400 \mathrm{~kb}$ should provide a reliable prenatal diagnosis. After extensive individual counselling diagnostic array analysis is now offered as a diagnostic choice in high risk pregnancies with fetal malformations and normal conventional chromosome analysis lacking further

Table 2 Copy number variants of unknown significance

\begin{tabular}{|c|c|c|c|c|c|c|}
\hline \multirow[t]{3}{*}{ CNV Nr. } & \multirow[t]{3}{*}{ Type of aberration } & BAC Clone-ID & \multirow{3}{*}{$\begin{array}{l}\text { Genome position } \\
\text { Hg18 }\end{array}$} & \multirow{3}{*}{$\begin{array}{l}\text { Maximal } \\
\text { size of } \\
\text { aberration }\end{array}$} & \multirow{3}{*}{$\begin{array}{l}\text { Chromosomal } \\
\text { region }\end{array}$} & \multirow[t]{3}{*}{ Interpretation } \\
\hline & & Start & & & & \\
\hline & & End & & & & \\
\hline \multirow[t]{2}{*}{1} & \multirow[t]{2}{*}{ Deletion (2 clones) } & RP5-998N21 & $147,596,844-147,726,269$ & \multirow[t]{2}{*}{$0.568 \mathrm{Mb}$} & \multirow[t]{2}{*}{$1 q 21.1 q 21.2$} & \multirow{2}{*}{$\begin{array}{l}\text { Unknown significance, } \\
\text { Not overlapping with the } \\
\text { recurrent deletion in the } \\
\text { 1q21.1 syndrome }\end{array}$} \\
\hline & & RP11-196G18 & $147,976,465-148,165,420$ & & & \\
\hline \multirow[t]{2}{*}{2} & \multirow[t]{2}{*}{ Duplication (4 clones) } & RP11-20B3 & $3,055,343-3,213,642$ & \multirow[t]{2}{*}{$0.656 \mathrm{Mb}$} & \multirow[t]{2}{*}{$5 p 15.33$} & \multirow{2}{*}{$\begin{array}{l}\text { Unknown significance, } \\
\text { Region deleted in } \\
\text { cri-du-chat syndrome }\end{array}$} \\
\hline & & CTD-2012M11 & $3,558,697-3,712,084$ & & & \\
\hline
\end{tabular}


diagnostic options or to determine the precise nature of a structural aberration detected by conventional karyotyping.

D'Amours et al. investigated a series of 49 fetuses with ultrasound anomalies using custom-designed whole genome oligo-arrays with different resolutions [26]. Out of 4 clinically significant anomalies, all detected by high resolution arrays, only 1 was smaller than $400 \mathrm{~kb}$, one was about $700 \mathrm{~kb}$ and 2 were potentially detectable by conventional chromosome analysis at sizes of about $8 \mathrm{Mb}$ and $14 \mathrm{Mb}$. Recent high resolution array studies using heterogeneous array designs including BAC-, oligo- and SNP arrays also focusing on detection rates in fetuses with congenital malformations [12,27-29] yielded variable detection rates of pathogenic CNVs in $1-3 \%$ up to $10 \%$ [13], and even up to $16 \%$ [14]. However, sizes of the clinically relevant aberrations were larger than $1 \mathrm{Mb}$ $[12,28,29]$. Even in the studies using whole genome SNParrays with a resolution higher than $100 \mathrm{~kb}$ clinically relevant aberrations were mainly in the range of $1 \mathrm{Mb}$ or more [13] or larger than $500 \mathrm{~kb}$ or $1 \mathrm{Mb}[14,25]$ in all but one case [14]. An overall detection rate of 5-6\% also including chromosomal anomalies detectable by conventional karyotyping was shown in array studies dealing with samples of heterogeneous clinical indications including fetal structural anomalies [12,30,31]. Hillman et al. concludes an overall detection rate of $3.6 \%$ regardless of the clinical indication and $5.3 \%$ for cases with ultrasound anomalies in his review and meta-analysis of this recent heterogeneous literature [32].

Referring to these results we would have expected to find at least one additional submicrosopic anomaly in our cohort examined. We focused, however, on pregnancies at risk for chromosomal anomalies as determined by first trimester screening, which has not been systematically considered in previous studies. Our patient cohort likely represents heterogeneous clinical indications, the main group being referred for increased nuchal translucency and elevated first trimester risk screening, whereas the proportion of fetuses with congenital malformations is comparatively low. Our results are in accordance with the findings of Faas et al. (personal communication, ESHG 2011 P05.32) who did not find any clinically relevant abnormalities in a cohort of 95 fetal samples with ultrasound anomalies including increased nuchal translucency when implementing a strategy for routine array diagnosis in parallel to QFPCR. High resolution whole genome arrays may therefore be specifically indicated in pregnancies with distinct fetal ultrasound anomalies or in the precise determination of rare structural chromosomal anomalies.

Our approach revealed a detection rate of $2 \%$ for $\mathrm{CNVs}$ of unknown significance at the given resolution, confirming that aCGH seems to be a safe approach in the diagnosis of first trimester pregnancies considered at high risk for chromosomal anomalies. In our experience aCGH is technically feasible and reliable as a first-line diagnostic test for prenatal samples, replacing laborious direct preparation of CVS as well as other rapid but less comprehensive testing procedures. We were able to provide a result in 3 to a maximum of 5 days after DNA extraction offering a superior coverage of pathogenic aberrations in the genome. Thus, aCGH provides the advantage to give patients a more complete genome analysis result in a short turn-around-time. High resolution arrays may gain further importance as we can expect that the clinical use of non-invasive diagnosis for common aneuploidies will increase the proportion of samples from high risk pregnancies obtained by invasive diagnosis. However, the appropriate array resolution still remains a matter of debate and may need to be adapted to the specific clinical indication and/or parental expectations. These would require a flexible resolution design of arrays and analysis software as well as the possibility to analyze one single patient in a (very) short turnaround time or multiple patients in parallel for diagnostic laboratories. Platforms requiring small initial DNA amount will be advantageous as the DNA amount from direct villi or amniocytes will be sufficient to allow array analysis as compared to time-consuming cell culturing for DNA extraction. For the time being cell cultures may be used as a back-up for confirmational FISH-analysis as well as follow-up of mosaic results if aCGH reveals an unbalanced structural aberration.

\section{Conclusion}

For the future application of aCGH in prenatal diagnosis we see the potential to use aCGH at a resolution of $400-600 \mathrm{~Kb}$ as a first line genetic test including the replacement of rapid testing methods such as direct preparation of chorionic villi, interphase-FISH and DNA-based QF-PCR and MLPA with a high diagnostic safety and accuracy. Considering results of recent studies high resolution arrays may be specifically indicated for pregancies with fetal malformations. So far, prenatal conventional chromosome analysis has been a rather standardized procedure, but array diagnosis may put pressure on prenatal professionals to think about personalizing diagnostic approaches.

\section{Material and Methods}

\section{Ethics approval}

The study was approved by the local ethics committee EKBB (Ref.Nr.EK: 62/08).

\section{Samples}

After technical optimization and validation of aCGH platforms by using anonymized samples with known 
chromosomal aberrations, we performed aCGH analysis of so far 100 prenatal samples from high risk pregnancies as defined in the study design. Of 100 patients 88 samples were included in the anonymized retrospective study. 12 patients seeked diagnostic testing, 2 of which had structural anomalies in conventional karyotyping, which were characterized more precisely by array, and 3 had mosaic results on which we reported in detail previously [20]. A survey of clinical indications is given in Table 3.

\section{Conventional chromosome analysis}

Conventional chromosome analysis was done on chorionic villi according to standard procedures evaluating numerical chromosome aberrations in direct preparation of cytotrophoblastic cells (QFQ-banding) and long-term culture of mesenchymal tissue for numerical and structural aberrations (GTG-banding, 500 band level). Direct preparation of chorionic villi allows the separation and analysis of cells from the mitotically active cytotrophoblastic layer after 24 hours. Chromosome analysis on amniotic fluid was performed according to standard protocols.

\section{DNA extraction}

The fetal sample was prepared for aCGH analyses using either direct genomic DNA from chorionic villi, DNA obtained from cultured CVS cells or DNA from amniocyte cultures. DNA for subsequent aCGH was extracted from 10-20 mg of direct chorionic villi or a T75 flask cell culture using the Qiagen DNeasy Blood and Tissue kit (Qiagen Germany Gmbh, Hilden) following the manufacturer's instructions. DNA from unprocessed and uncultured direct villi represents a

\begin{tabular}{lcc}
$\begin{array}{l}\text { Table } 3 \text { Clinical indications for invasive prenatal } \\
\text { diagnosis in our retrospective cohort including } \mathbf{1 2} \\
\text { diagnostic samples }\end{array}$ & $\begin{array}{c}\text { Number of } \\
\text { samples }\end{array}$ & $\begin{array}{c}\text { \% of total number of } \\
\text { samples }\end{array}$ \\
\hline Indication & 26 & 26.5 \\
\hline NT>3 mm & 9 & 9.2 \\
Risk of 1:10 or higher in & & 22.5 \\
first trimester screening & 22 & $\mathbf{5 8 . 2}$ \\
Both (NT>3mm & & 10.2 \\
and risk > 1:10) & $\mathbf{5 7 *}$ & 10.2 \\
Subtotal & 10 & 21.4 \\
IUGR & 10 & $\mathbf{1 0 0}$ \\
IUGR and malformation & $21^{* *}$ & $\mathbf{9 8 ^ { * * * }}$ \\
Malformation(s) &
\end{tabular}

* investigation of 2 mosaic and 1 chromosomal structural anomaly included ** investigation of 1 mosaic result and 1 chromosomal structural anomaly included.

*** 2 samples failed analysis. mixture of cytotrophoblastic and mesenchymal cell sources whereas DNA from cultured cells is of mesenchymal origin. Due to experiences when studying aCGH in the presence of fetoplacental mosaicism [20] initial lysis of chorionic villi by proteinase $\mathrm{K}$ was followed by collagenase digestion to increase the proportion of DNA from mesenchymal cells. RNase treatment (RNase A, Qiagen Germany Gmbh, Hilden) was added to remove the high levels of RNA in these tissue types. DNA concentration and purity was determined using a NanoDrop 1000 spectrophotometer (Witec AG, Littau, Switzerland).

\section{Array comparative genomic hybridization (aCGH)}

aCGH was performed on extracted DNA in 95 study samples using the Constitutional Chip ${ }^{\circledR} 4.0$ (PerkinElmer, Turku Finland) BAC platform. Validation analysis was done on 20 samples with known chromosomal aberrations. The BAC array contains more than 5200 distinct clones in total with a median probe spacing of $600 \mathrm{~kb}$. Targeted regions with higher clone density are chromosomal regions of interest (>1200 clones), subtelomeric regions with coverage by more than $900 \mathrm{BAC}$ clones, pericentromeric regions with enhanced coverage $(>100$ clones) and the $\mathrm{X}$-chromosome with near to tiling coverage for high resolution detection of chromosomal abnormalities across the X-chromosome. An additional back-bone of more than $2000 \mathrm{BAC}$ clones provides an average resolution of less than $1 \mathrm{Mb}$ in non-targeted areas. Two $2 \mu \mathrm{g}$ of purified DNA is required for analysis. Labelling and hybridization of test and reference DNA was performed according to the manufacturer's protocols. Test and reference DNA were labelled by $\mathrm{Cy} 3$ and $\mathrm{Cy} 5$ with reciprocal labelling reactions and hybridized for 16-18 hours on two independent arrays (dye-swap) which allows to normalize intensity bias introduced by different dye properties. Arrays were then subjected to 4 washings according to the protocol. Two colour scanning was performed by the PerkinElmer ${ }^{\circledR}$ Inc.'s ScanArray ${ }^{\circledR}$ Microarray Scanner. Acquisition of the microarray images was performed with the ScanArray Express software, Microarray Analysis System, version 4.0.0.0004. Data extraction, analysis and visualisation were done by the Oneclick CGH software, version 4.3.3., Perkin Elmer Edition. Classification of gain and loss was based on the software's segmentation algorithm with a threshold of a 1.2 ratio $(0.26 \log 2$ ratio). A minimum of two consecutive clones indicating copy number variation was considered as a relevant aberration.

Due to a technology change in our laboratory the Affymetrix Cytogenetics ${ }^{\circledR}$ Whole Genome 2.7 M array, which is based on 2.7 million copy number markers $(\mathrm{CN}$ markers) and additional 400,000 SNPs (average marker spacing $1086 \mathrm{bp)}$ was used in further 5 samples for 
diagnostic purposes. We use this platform for the postnatal investigation of patients with syndromic and non-syndromic intellectual disability with an overall detection rate of pathogenic CNVs of $12.2 \%$ in patients with previously normal karyotype [33]. Validation for prenatal tissues was performed on 16 control samples. Only $150 \mathrm{ng}$ of purified DNA is required for analysis which represents a significant advantage over the $2 \mu \mathrm{g}$ required for the BAC array when using prenatal tissues. Single colour hybridization was performed according to the manufacturer's protocol. Arrays were then scanned by the GeneChip Scanner $30007 \mathrm{G}$ system (Affymetrix Inc. Santa Clara, CA, USA). Results were analyzed by the Affymetrix Chromosome Analysis Suite $\left(\mathrm{ChAS}^{\circledR}\right)$ software. Aberrations were filtered by the software up to a minimal size of $400 \mathrm{kB}$ for deletions and duplications. Limits were decided based on our own previous experiences and existing literature. Results were reassessed manually for CNVs.

\section{Fluorescence-in-situ hybridization (FISH)}

FISH was used for confirmation of dosage imbalances suspected to be pathogenic in the samples when possible on remaining tissue culture. Confirmation or exclusion of involvement in familial rearrangements in parental samples was not realizable due to the retrospective design of the study. FISH was performed on metaphase slides according to the manufacturer's hybridization protocols. Clones from Abbott and Kreatech were used when available for the aberrant region and for control hybridization. Clones provided by BlueGnome were chosen within specific regions when the former were not available.

\section{Interpretation of CNV significance}

The pathogenicity of the CNVs was assessed using the guidelines recently discussed [34-37]. All detected CNVs were compared against the database of genomic variants (http://projects.tcag.ca/variation). If an aberration was not reported as a benign variant, it was, in correlation with the phenotype, analyzed for gene content, function and genomic position potentially in relation to the phenotype or a particular phenotypic trait, compared with entries in the Decipher database (http://decipher.sanger.ac.uk) or Ecaruca (www.ecaruca.net) and evaluated against existing literature for known syndromes and overlapping causal aberrations. Aberrations likely to be causative were confirmed by FISH. Aberrations of unknown significance were documented, however, parental array analysis was not possible for samples included in the retrospective testing.

\section{Abbreviations}

aCGH: Array comparative genomic hybridization; CNV: Copy number variant CVS: Chorionic villous sampling; AC: Amniocentesis; ID: Intellectual disability; MCA: Multiple congenital anomalies; FISH: Fluorescence-in-situ-hybridization

\section{Competing interests}

All authors declare no competing interests.

\section{Author's contributions}

IF and PM designed and coordinated the study and wrote the manuscript. IF collected and interpreted clinical and array data. AK and ST are responsible for prenatal ultrasound and invasive procedures and participated in patient recruitment. VK performed the BAC-arrays. FW, IF, KH and PM are responsible for array interpretation. All authors read and approved the final manuscript.

\section{Details of ethics approval}

The study was approved by the local ethics committee EKBB (Ref.Nr.EK: 62/ 08). For diagnostic testing individual patients' consent was obtained within the counselling process.

\section{Acknowledgements}

The work has been partially supported by the research grant of the University of Basel (DMS2058) and the "Intramurale Forschungsförderung" of the University Children's Hospital UKBB, Basel. We received further support for consumables by Perkin Elmer, Turku, Finland.

We thank the patients for their gracious participation and support. We are grateful to the technicians from our laboratories for their skilful help.

\section{Author details}

${ }^{1}$ Dr. med. Isabel Filges, Division of Medical Genetics, University Children's Hospital and Department of Biomedicine, University of Basel, Burgfelderstrasse 101, Building J, CH-4055, Basel, Switzerland. ' 2 Ultrasound Unit, Department of Obstetrics and Gynecology, University Hospital, Basel, Switzerland. ${ }^{3}$ Department of Medical Genetics, BC Children's and Women's Hospital, Child and Family Research Institute, University of British Columbia, Box 153, 4480 Oak Street, Vancouver, BC V6H 3V4, Canada.

Received: 31 May 2012 Accepted: 30 July 2012

Published: 17 September 2012

\section{References}

1. Ekelund C, Jørgensen F, Petersen O, Sundberg K, Tabor A: Impact of a new national screening policy for Down's syndrome in Denmark: population based cohort study. BMJ 2008, 337:a2547.

2. Lichtenbelt KD, Alizadeh BZ, Scheffer PG, Stoutenbeek P, Schielen PC, Page-Christiaens LC, Schuring-Blom GH: Trends in the utilization of invasive prenatal diagnosis in The Netherlands during. Prenat Diagn 2000-2009, 31(8):765-772.

3. Chen EZ, Chiu RW, Sun H, Akolekar R, Chan KC, Leung TY, Jiang P, Zheng YW, Lun FM, Chan LY, Jin Y, Go AT, Lau ET, To WW, Leung WC, Tang RY, Au-Yeung SK, Lam H, Kung YY, Zhang X, van Vugt JM, Minekawa R, Tang MH, Wang J, Oudejans CB, Lau TK, Nicolaides KH, Lo YM: Noninvasive prenatal diagnosis of fetal trisomy 18 and trisomy 13 by maternal plasma DNA sequencing. PLoS One 2011, 6(7):e21791.

4. Liao GJ, Lun FM, Zheng YW, Chan KC, Leung TY, Lau TK, Chiu RW, Lo YM: Targeted massively parallel sequencing of maternal plasma DNA permits efficient and unbiased detection of fetal alleles. Clin Chem 2011, 57(1):92-101.

5. Lo YM, Chan $\mathrm{KC}$, Sun $\mathrm{H}$, Chen EZ, Jiang $\mathrm{P}$, Lun FM, Zheng $\mathrm{YW}$, Leung TY, Lau TK, Cantor CR, Chiu RW: Maternal plasma DNA sequencing reveals the genome-wide genetic and mutational profile of the fetus. Sci Trans/ Med 2010, 2(61):61. ra91.

6. Chiu RW, Akolekar R, Zheng YW, Leung TY, Sun H, Chan KC, Lun FM, Go AT, Lau ET, To WW, Leung WC, Tang RY, Au-Yeung SK, Lam H, Kung YY, Zhang $X$, van Vugt JM, Minekawa R, Tang MH, Wang J, Oudejans CB, Lau TK, Nicolaides KH, Lo YM: Non-invasive prenatal assessment of trisomy 21 by multiplexed maternal plasma DNA sequencing: large scale validity study. BMJ 2011, 342:C7401.

7. Chiu RW, Lo YM: Non-invasive prenatal diagnosis by fetal nucleic acid analysis in maternal plasma: the coming of age. Semin Fetal Neonatal Med 2011, 16(2):88-93. 
8. Papageorgiou EA, Karagrigoriou A, Tsaliki E, Velissariou V, Carter NP, Patsalis PC: Fetal-specific DNA methylation ratio permits noninvasive prenatal diagnosis of trisomy 21. Nat Med 2011, 17(4):310-313.

9. Miller DT: Genetic testing for autism: recent advances and clinical implications. Expert Rev Mol Diagn 2010, 10(7):837-840

10. Manning M, Hudgins L: Committee PPaG. Array-based technology and recommendations for utilization in medical genetics practice for detection of chromosomal abnormalities. Genet Med 2010, 12(11):742-745.

11. Vialard F, Molina Gomes D, Leroy B, Quarello E, Escalona A, Le Sciellour C, Serazin V, Roume J, Ville $Y$, de Mazancourt P, Selva J: Array Comparative Genomic Hybridization in Prenatal Diagnosis: Another Experience. Fetal Diagn Ther 2009, 25(2):277-284

12. Van den Veyver I, Patel A, Shaw C, Pursley A, Kang S, Simovich M, Ward P, Darilek S, Johnson A, Neill S, Bi W, White L, Eng C, Lupski J, Cheung S, Beaudet A: Clinical use of array comparative genomic hybridization (aCGH) for prenatal diagnosis in 300 cases. Prenat Diagn 2009, 29(1):29-39.

13. Tyreman M, Abbott K, Willatt L, Nash R, Lees C, Whittaker J, Simonic I: High resolution array analysis: diagnosing pregnancies with abnormal ultrasound findings. J Med Genet 2009, 46(8):531-541.

14. Faas BH, van der Burgt I, Kooper AJ, Pfundt R, Hehir-Kwa JY, Smits AP, de Leeuw N: Identification of clinically significant, submicroscopic chromosome alterations and UPD in fetuses with ultrasound anomalies using genome-wide 250 k SNP array analysis. J Med Genet 2010, 47(9):586-594.

15. Friedman J: High-resolution array genomic hybridization in prenatal diagnosis. Prenat Diagn 2009, 29(1):20-28

16. Bui TH, Vetro A, Zuffardi O, Shaffer LG: Current controversies in prenata diagnosis 3: is conventional chromosome analysis necessary in the post-array CGH era? Prenat Diagn 2011, 31(3):235-243.

17. Committee ACOG: Opinion No. 446: array comparative genomic hybridization in prenatal diagnosis. Obstet Gynecol 2009, 114(5):1161-1163.

18. Manegold G, Tercanli S, Struben H, Huang D, Kang A: Is a Routine Ultrasound in the Third Trimester Justified? - Additional Fetal Anomalies Diagnosed After Two Previous Unremarkable Ultrasound Examinations. Ultraschall Med 2011, 32(4):381.

19. Hauge X, Raca G, Cooper S, May K, Spiro R, Adam M, Martin CL: Detailed characterization of, and clinical correlations in, 10 patients with distal deletions of chromosome 9p. Genet Med 2008, 10(8):599-611.

20. Filges I, Kang A, Klug V, Wenzel F, Heinimann K, Tercanli S, Miny P: aCGH on chorionic villi mirrors the complexity of fetoplacental mosaicism in prenatal diagnosis. Prenat Diagn 2011, 31(5):473-478.

21. Leung TY, Vogel I, Lau TK, Chong W, Hyett JA, Petersen OB, Choy KW: Identification of submicroscopic chromosomal aberrations in fetuses with increased nuchal translucency and an apparently normal karyotype. Ultrasound Obstet Gynecol 2011, 38(3):307-310.

22. Pergament E, Alamillo C, Sak K, Fiddler M: Genetic assessment following increased nuchal translucency and normal karyotype. Prenat Diagn 2011 31(3):307-310.

23. Houweling AC, de Mooij YM, van der Burgt I, Yntema HG, Lachmeijer AM, Go AT: Prenatal detection of Noonan syndrome by mutation analysis of the PTPN11 and the KRAS genes. Prenat Diagn 2010, 30(3):284-286.

24. Lee KA, Williams B, Roza K, Ferguson H, David K, Eddleman K, Stone J, Edelmann L, Richard G, Gelb BD, Kornreich R: PTPN11 analysis for the prenatal diagnosis of Noonan syndrome in fetuses with abnormal ultrasound findings. Clin Genet 2009, 75(2):190-194.

25. Miller DT, Adam MP, Aradhya S, Biesecker LG, Brothman AR, Carter NP, Church DM, Crolla JA, Eichler EE, Epstein CJ, Faucett WA, Feuk L, Friedman JM, Hamosh A, Jackson L, Kaminsky EB, Kok K, Krantz ID, Kuhn RM, Lee C, Ostell JM, Rosenberg C, Scherer SW, Spinner NB, Stavropoulos DJ, Tepperberg JH, Thorland EC, Vermeesch JR, Waggoner DJ, Watson MS, Martin CL, Ledbetter DH: Consensus statement: chromosomal microarray is a first-tier clinical diagnostic test for individuals with developmental disabilities or congenital anomalies. Am J Hum Genet 2010, 86(5):749-764.

26. D`Amours G, Kibar Z, Mathonnet G, Fetni R, Tihy F, Désilets V, Nizard S, Michaud $J$, Lemyre $E$ : Whole-genome array CGH identifies pathogenic copy number variations in fetuses with major malformations and a normal karyotype. Clin Genet 2012, 81(2):128-141.

27. Srebniak M, Boter M, Oudesluijs G, Joosten M, Govaerts L, Van Opstal D, Galjaard RJ: Application of SNP array for rapid prenatal diagnosis: implementation, genetic counselling and diagnostic flow. Eur J Hum Genet 2011, 19(12):1230-1237.

28. Kleeman L, Bianchi D, Shaffer L, Rorem E, Cowan J, Craigo S, Tighiouart H, Wilkins-Haug L: Use of array comparative genomic hybridization for prenatal diagnosis of fetuses with sonographic anomalies and normal metaphase karyotype. Prenat Diagn 2009, 29(13):1213-1217.

29. Coppinger J, Alliman S, Lamb A, Torchia B, Bejjani B, Shaffer L: Wholegenome microarray analysis in prenatal specimens identifies clinically significant chromosome alterations without increase in results of unclear significance compared to targeted microarray. Prenat Diagn 2009, 29(12):1156-1166.

30. Sahoo T, Cheung S, Ward P, Darilek S, Patel A, del Gaudio D, Kang S, Lalani S, Li J, McAdoo S, Burke A, Shaw C, Stankiewicz P, Chinault A, Van den Veyver I, Roa B, Beaudet A, Eng C: Prenatal diagnosis of chromosomal abnormalities using array-based comparative genomic hybridization. Genet Med 2006, 8(11):719-727.

31. Maya I, Davidov B, Gershovitz L, Zalzstein Y, Taub E, Coppinger J, Shaffer LG, Shohat M: Diagnostic utility of array-based comparative genomic hybridization $(\mathrm{aCGH})$ in a prenatal setting. Prenat Diagn 2010, 30(12-13):1131-1137.

32. Hillman SC, Pretlove S, Coomarasamy A, McMullan DJ, Davison EV, Maher ER, Kilby MD: Additional information from array comparative genomic hybridization technology over conventional karyotyping in prenatal diagnosis: a systematic review and meta-analysis. Ultrasound Obstet Gynecol 2011, 37(1):6-14

33. Filges I, Suda L, Weber P, Datta AN, Fischer D, Dill P, Glanzmann R, Benzing J, Hegi L, Wenzel F, Huber AR, Mori AC, Miny P, Röthlisberger B: High resolution array in the clinical approach to chromosomal phenotypes. Gene 2012, 495(2):163-169. 10.

34. Rodriguez-Revenga L, Mila M, Rosenberg C, Lamb A, Lee C: Structural variation in the human genome: the impact of copy number variants on clinical diagnosis. Genet Med 2007, 9(9):600-606.

35. Lee $C$, lafrate $A$, Brothman A: Copy number variations and clinical cytogenetic diagnosis of constitutional disorders. Nat Genet 2007, 39(7 Suppl):S48-S54.

36. Carter NP: Methods and strategies for analyzing copy number variation using DNA microarrays. Nat Genet 2007, 39(7 Suppl):S16-S21.

37. Vermeesch JR, Fiegler H, de Leeuw N, Szuhai K, Schoumans J, Ciccone R, Speleman F, Rauch A, Clayton-Smith J, Van Ravenswaaij C, Sanlaville D, Patsalis PC, Firth H, Devriendt K, Zuffardi O: Guidelines for molecular karyotyping in constitutional genetic diagnosis. Eur J Hum Genet 2007, 15(11):1105-1114.

doi:10.1186/1755-8166-5-38

Cite this article as: Filges et al:: Array comparative genomic

hybridization in prenatal diagnosis of first trimester pregnancies at high risk for chromosomal anomalies. Molecular Cytogenetics 2012 5:38.

\section{Submit your next manuscript to BioMed Central and take full advantage of:}

- Convenient online submission

- Thorough peer review

- No space constraints or color figure charges

- Immediate publication on acceptance

- Inclusion in PubMed, CAS, Scopus and Google Scholar

- Research which is freely available for redistribution 